\title{
Broader HIV-1 neutralizing antibody responses induced by envelope glycoprotein mutants based on the EIAV attenuated vaccine
}

\author{
Lianxing Liu' ${ }^{1,2,3}$, Yanmin Wan ${ }^{1,4}$, Lan $W^{1}{ }^{1}$, Jianping Sun ${ }^{1}$, Huiguang $\mathrm{Li}^{1}$, Haishan Li ${ }^{1}$, Liying Ma ${ }^{1}$, Yiming Shao ${ }^{1,2^{*}}$
}

\begin{abstract}
Background: In order to induce a potent and cross-reactive neutralizing antibody (nAb), an effective envelope immunogen is crucial for many viral vaccines, including the vaccine for the human immunodeficiency virus (HIV). The Chinese equine infectious anemia virus (EIAV) attenuated vaccine has controlled the epidemic of this virus after its vaccination in over 70 million equine animals during the last 3 decades in China. Data from our past studies demonstrate that the Env protein of this vaccine plays a pivotal role in protecting horses from both homologous and heterogeneous EIAV challenges. Therefore, the amino acid sequence information from the Chinese EIAV attenuated vaccine, in comparison with the parental wild-type EIAV strains, was applied to modify the corresponding region of the envelope glycoprotein of HIV-1 CN54. The direction of the mutations was made towards the amino acids conserved in the two EIAV vaccine strains, distinguishing them from the two wild-type strains. The purpose of the modification was to enhance the immunogenicity of the HIV Env.

Results: The induced nAb by the modified HIV Env neutralized HIV-1 B and $B^{\prime} / C$ viruses at the highest titer of 1:270. Further studies showed that a single amino acid change in the $\mathrm{C} 1$ region accounts for the substantial enhancement in induction of anti-HIV-1 neutralizing antibodies.

Conclusions: This study shows that an HIV envelope modified by the information of another lentivirus vaccine induces effective broadly neutralizing antibodies. A single amino acid mutation was found to increase the immunogenicity of the HIV Env.
\end{abstract}

\section{Background}

Both EIAV and HIV are members of the Lentivirus genus of the Retroviridae family [1,2]. Although the clinical manifestations of infections by EIAV and HIV are different, the underlying mechanisms of persistence and pathogenesis are very similar [3,4]. These similarities are based on the common genetic organization, the molecular mechanism of viral replication, and the conformational structures of the viral structural proteins [5-9]. Most chronically infected horses survive the subclinical carrier phase after recurring cycles of fever, anemia, weight loss, and thrombocytopenia $[10,11]$. Therefore,

\footnotetext{
* Correspondence: yshao@bbn.cn

${ }^{1}$ State Key Laboratory for Infectious Diseases Prevention and Control, National Center for AIDS/STD Control and Prevention, Chinese Center for Disease Control and Prevention, 155 Changbai Road, Changping District, Beijing 102206, China

Full list of author information is available at the end of the article
}

EIAV has been used as a model to study HIV-1 persistence, pathogenesis, and immune responses [12-17].

Despite many years of ongoing research, an effective HIV vaccine has not yet been developed. The first successful lentivirus vaccine was an EIAV vaccine, which was made 30 years ago $[18,19]$. Therefore, the EIAV vaccine can serve as a good model to identify the mechanisms of immune responses against lentiviruses and shed light on how to design an effective HIV vaccine. Studies on the animal models of EIAV, FIV, and SIV showed that attenuated vaccines can be highly effective against infection by wild-type strains [18-22]. The Chinese EIAV donkey-leukocyte attenuated vaccine (DLV) was developed through long-term tissue culture attenuation (123 passages) from a highly pathogenic EIAV strain D510. The latter was obtained from in vivo passages (17 and 117 passages in horses and donkeys respectively) of a field EIAV isolates, LN40 strain. The
C Biomed Central

C 2010 Liu et al; licensee BioMed Central Ltd. This is an Open Access article distributed under the terms of the Creative Commons Attribution License (http://creativecommons.org/licenses/by/2.0), which permits unrestricted use, distribution, and reproduction in any medium, provided the original work is properly cited. 
DLV vaccines have turned out to be effective, with about $80 \%$ of vaccinated horses resisting challenge by homogeneous and heterogeneous virulent EIAV strains $[18,19]$.

The envelope protein of EIAV plays a pivotal role in the receptor binding on target cells, the subsequent entry into the cell, and the induction of humoral immune responses [23-25]. Previous work with EIAV, FIV as well as SIV has shown that there is a progressive maturation of Env-specific antibody responses to various attenuated lentiviral vaccines [15,26-28]. The mature immune responses including high titer and high avidity can be enhanced by a modified Env, leading to protective vaccine immunity [15,26-29]. Towards this objective, the current studies were conducted. We enhanced the immunogenicity of the HIV Env by making certain envelope mutations associated with the effective EIAV vaccine.

\section{Results}

\section{Vaccines Construction}

From the sequence analysis of two Chinese vaccinederived wild-type EIAV strains (LN40 and D510) and two vaccine virus strains (DLV and FDDV), 10 consensus amino acid mutations were identified in the EIAV Env region [2] (Figure 1a). We modified the HIV-1 gp145 DNA vaccine and recombinant vaccinia vaccine by introducing all of the EIAV amino acid mutations (Table 1 and Figure 1b). They were based on the structural information of the attenuated EIAV vaccine $[5,6]$ (Figure 1c). We used the gp145 derived from CN54 [Genbank: AX149771], which belongs to the most prevalent CRF BC_07 in China [30], as the template. Details on these constructions are provided in the Methods.

\section{Gp145-10 M enhanced the humoral immune responses} Env-specific binding antibody responses

$\mathrm{BALB} / \mathrm{c}$ mice were immunized four times with the DNA vaccine SV1.0, SV145, and SV145-10 M at intervals of two weeks and were sacrificed at three weeks after the last inoculation (Figure 2a). The sera of the SV145$10 \mathrm{M}$ group produced binding antibodies at a titer of 1:800. This amount of antibodies was 3.5 times higher than that elicited by SV145 ( $=0.0020)$. The mock vector (SV1.0) control group only generated a background of antibodies at $<1: 100$ (Figure 2b).

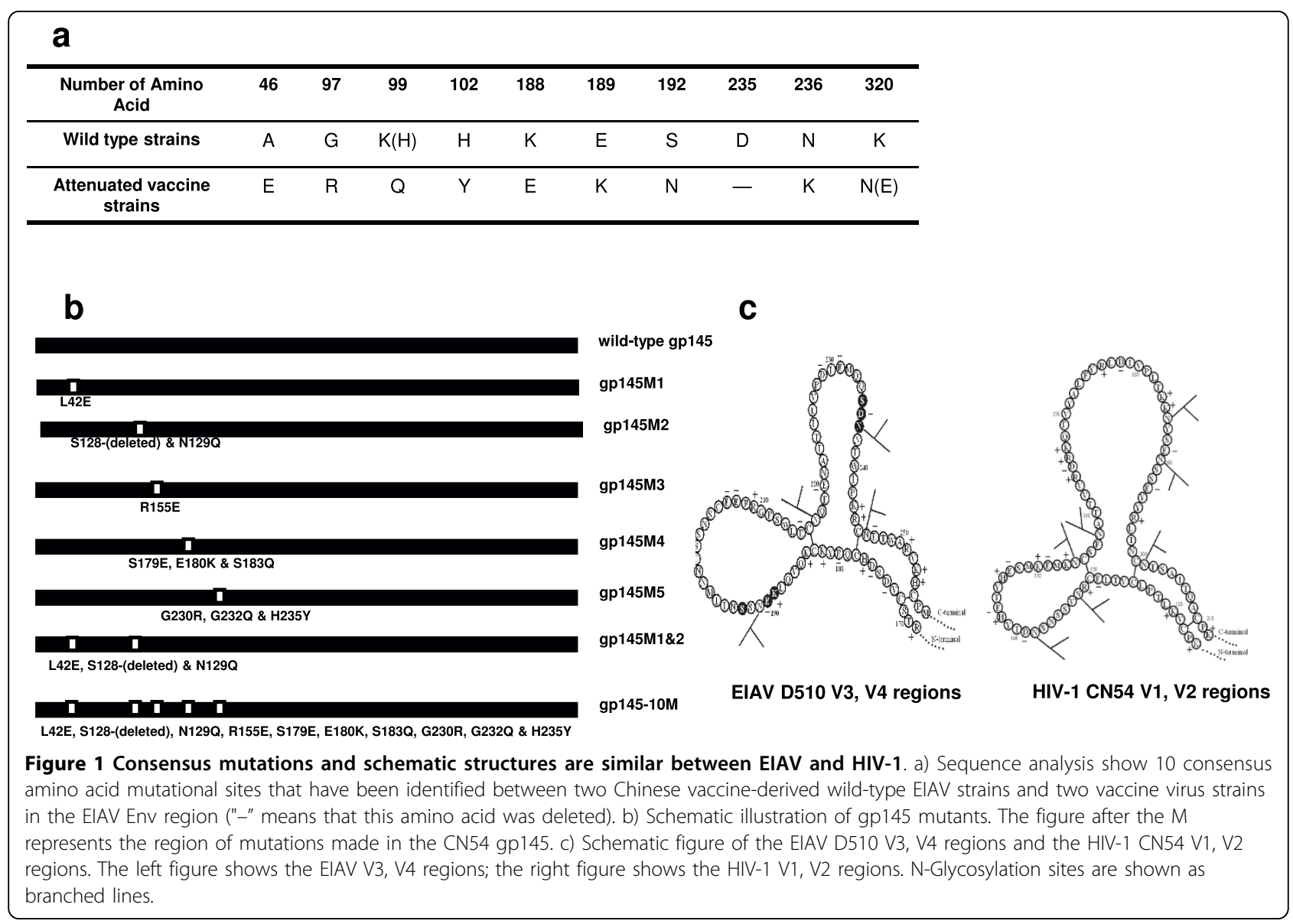


Table 1 List of the primers used in PCR for modification

\begin{tabular}{|c|c|}
\hline Name & Primer sequence $\left(5^{\prime}-3^{\prime}\right)$ \\
\hline CN54145F & GCTCTAGAGATATCGACACCATGGACAGGGCCAAGCTGCTGCTG \\
\hline CN54145R & GTGAACAGGGTGAGGCAGGGCTACTGAGGATCCGTCGACCG \\
\hline $145 \mathrm{M} 1 \mathrm{u}$ & ACCACCGAGTTCTGCGCCAGCGACG \\
\hline $145 \mathrm{M} 1 \mathrm{~d}$ & CGCAGAACTCGGTGGTGGTGGCGCCCTTCCACACGG \\
\hline $145 \mathrm{M} 2 \mathrm{u}$ & AACCAGGACACCTACCACGAGACC \\
\hline $145 \mathrm{M} 2 \mathrm{~d}$ & СTCCTCGTGGTAGGTGTCCTGGTTGCTGCTCACGTTCCT \\
\hline $145 \mathrm{M} 3 \mathrm{u}$ & ACCGTGGTGGAGGACAGGAAGCAGAC \\
\hline $145 \mathrm{M} 3 \mathrm{~d}$ & TTCCTGTCCTCCACCACGGTGGTGGCGTTG \\
\hline $145 \mathrm{M} 4 \mathrm{u}$ & CTACGAGAAGAACAGCCAGGAGTACTACAGGCTGATC \\
\hline $145 \mathrm{M} 4 \mathrm{~d}$ & CCTGGCTGTTCTTCTCGTAGTTCTTCTTGGT \\
\hline $145 \mathrm{M} 5 \mathrm{u}$ & ATCTTCAACCGCACCCAGCCCTGCTACAACGTGAGCACCG \\
\hline $145 \mathrm{M} 5 \mathrm{~d}$ & GTTGTAGCAGGGCTGGGTGCGGTTGAAGATCTTGTC \\
\hline
\end{tabular}

All mutations in primers are marked with bold text.

\section{Neutralizing antibody responses in BALB/c mice}

Neutralizing antibodies were determined with HIV-1 primary isolates $\left(\mathrm{B}^{\prime} / \mathrm{C}\right.$ clade isolates XJDC6371, XJDC6431, XJDC0793, CBJB105, CBJB248 and B' clade isolate 020201300). The serum neutralization titer was determined by assessing whether the sera could neutralize $50 \%$ of the virus in triplicate. If the value of $1 / 50 \%$ neutralization titer is 6 , it means the sera neutralized more than $50 \%$ of the virus at the dilution of $1: 6$. Sera from all gp145 immunized mice failed to neutralize any of the $\mathrm{B}^{\prime} / \mathrm{C}$ clade isolates even at the lowest titer of 1:6. Notably, the sera of the gp145-10 M immunized mice neutralized all five of the $\mathrm{B}^{\prime} / \mathrm{C}$ clade primary viruses and virus 020201300. Moreover, all mice neutralizing antibody titers from the gp145-10 $\mathrm{M}$ group were higher than 1:12 and neutralized $\mathrm{B}^{\prime} / \mathrm{C}$ clade viruses XJDC6431, XJDC0793, CBJB105, CBJB248 higher than 1:24 (Table 2).

\section{Neutralizing antibody responses in guinea pigs}

Neutralizing antibodies at a titer 1:10 in guinea pigs model were tested at four and six weeks after the last inoculation (Figure 3a). At least three of four sera from gp145-10M-immunized guinea pigs neutralized all of the $\mathrm{B}^{\prime} / \mathrm{C}$ clade and $\mathrm{B}^{\prime}$ clade viruses at six weeks (Figure $3 \mathrm{~b}$ ), and similar results were found at four weeks (data not shown). Notably, the neutralization frequency in gp145-10M-immunized animals was 2.5 fold higher than that of gp145-immunized animals at the titer $\geq 1: 10$ (Figure 3b). Moreover, at least two of four sera collected

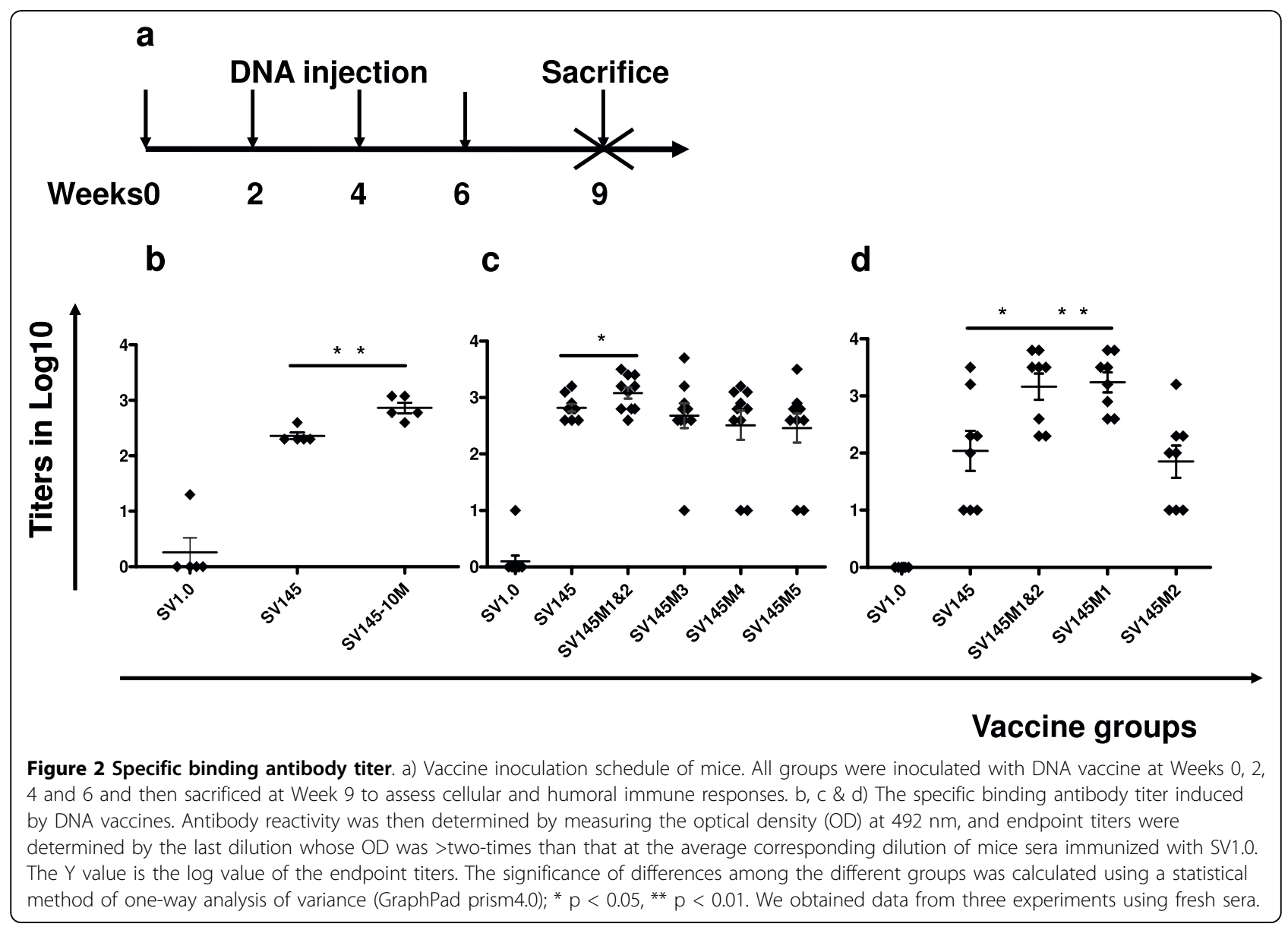


Table 2 Neutralization titer against HIV-1 clinical isolates in BALB/c mice

\begin{tabular}{|c|c|c|c|c|c|c|}
\hline \multirow[t]{2}{*}{ Vaccine groups } & \multicolumn{6}{|c|}{ Neutralization titer against HIV-1 isolates } \\
\hline & XJDC6371 & XJDC6431 & XJDC0793 & CBJB105 & CBJB248 & 020101300 \\
\hline SV145 & $<6$ & $<6$ & $<6$ & $<6$ & $<6$ & $>12$ \\
\hline SV145-10M & $>12$ & $>24$ & $>24$ & $>24$ & $>24$ & $>12$ \\
\hline SV145M1\&2 & $<6$ & $>24$ & $>24$ & $>24$ & $>24$ & $>24$ \\
\hline SV145M1 & $<6$ & $>24$ & $>24$ & $>24$ & $>24$ & $>24$ \\
\hline SV145M2 & $<6$ & $>12$ & $>12$ & $>12$ & $>12$ & $>12$ \\
\hline SV145M3 & $<6$ & $<6$ & $<6$ & $<6$ & $>12$ & $>12$ \\
\hline SV145M4 & $<6$ & $<6$ & $<6$ & $<6$ & $>12$ & $>12$ \\
\hline SV145M5 & $<6$ & $<6$ & $<6$ & $<6$ & $<6$ & $<6$ \\
\hline
\end{tabular}

The neutralization was conducted by using a panel of clinical isolates in PBMCs with 50\% inhibitory dose. Gp145-10 M, gp145M1\&2, gp145M1 and 145M2 groups could neutralize HIV-1 isolates at the highest titer of 1:24, other than XJDC6371. The single N-glycosylation site deletion in the V1 loop designated as gp145M2 could induce broader neutralizing antibodies against five clinical isolates at a titer of 1:12.

from the gp145-10M-immunized guinea pigs showed $80 \%$ neutralization at the titer of $\geq 1: 10$ (data not shown). In contrast, only one of four sera collected from the gp145-immunized animals had 50\% neutralization at the titer of $\geq 1: 10$; and only three possible events were found in the gp145-immunized group. Lastly, but most importantly, antibodies induced by gp145-10 M neutralized all HIV-1 isolates and pseudotyped viruses at the highest endpoint titers of 1:270 (Figure 4a,b). The mean neutralization titers from mock-, gp145- and gp14510M-immunized groups against all viruses were $0,1: 16$ and $1: 71$, respectively (Figure $4 \mathrm{a}$ ). Two sera of the
gp145-10M-immunized guinea pigs neutralized all viruses at titers of $1: 98$ and 1:158.

\section{Linear antibody epitope mapping}

The results of the PLL-ELISA demonstrated that different antibodies to specific linear epitopes were induced among gp145- and gp145-10M-immunized mice (Figure $5)$. In the $\mathrm{C} 1$ region, both gp145 and gp145-10 M induced antibodies to peptide 4840, and the latter enhanced the response. The gp145-10M-immunized animals failed to generate antibodies to peptides 4838,4859 and 4860, but they induced strong antibody responses to

\section{a}

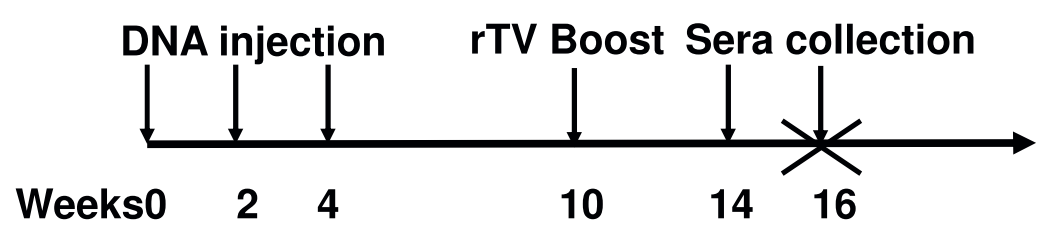

b

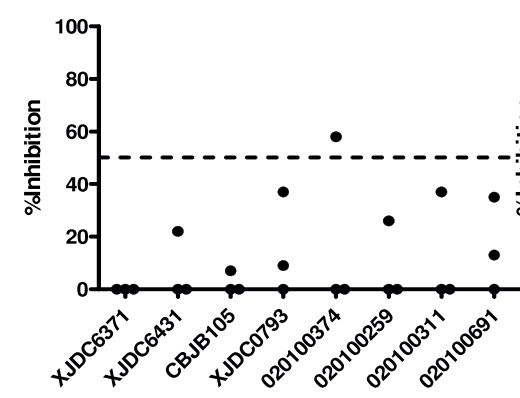

Mock

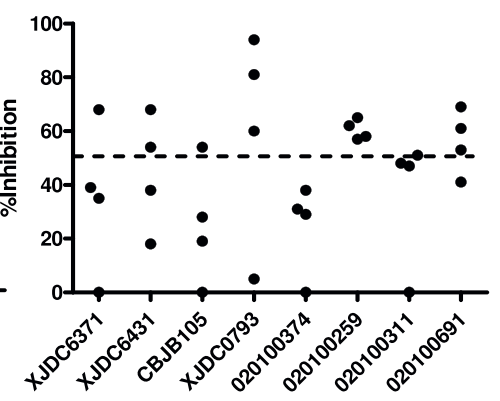

gp145

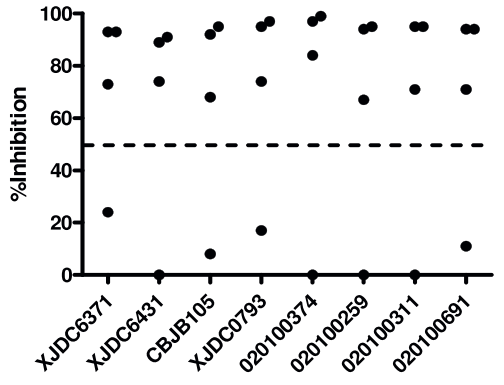

gp145-10M

Figure 3 Inhibition of HIV by sera of immunized guinea pigs at the titer of 1:10. a) Vaccine inoculation schedule of guinea pigs. All groups were inoculated with DNA vaccine at weeks 0,2,4 and then boosted with rTV at week 10. Sera after last immunization were collected at week 14 and 16. b) Comparative inhibition of HIV-1 infection by sera collected at week 16 from mock-, gp145- and gp145-10M-immunized guinea pigs. The neutralizing experiment was conducted by using a panel of clinical HIV-1 isolates from PBMCs in TZM-bl cells. The dotted line in the figure indicates the $50 \%$ inhibition rate. 


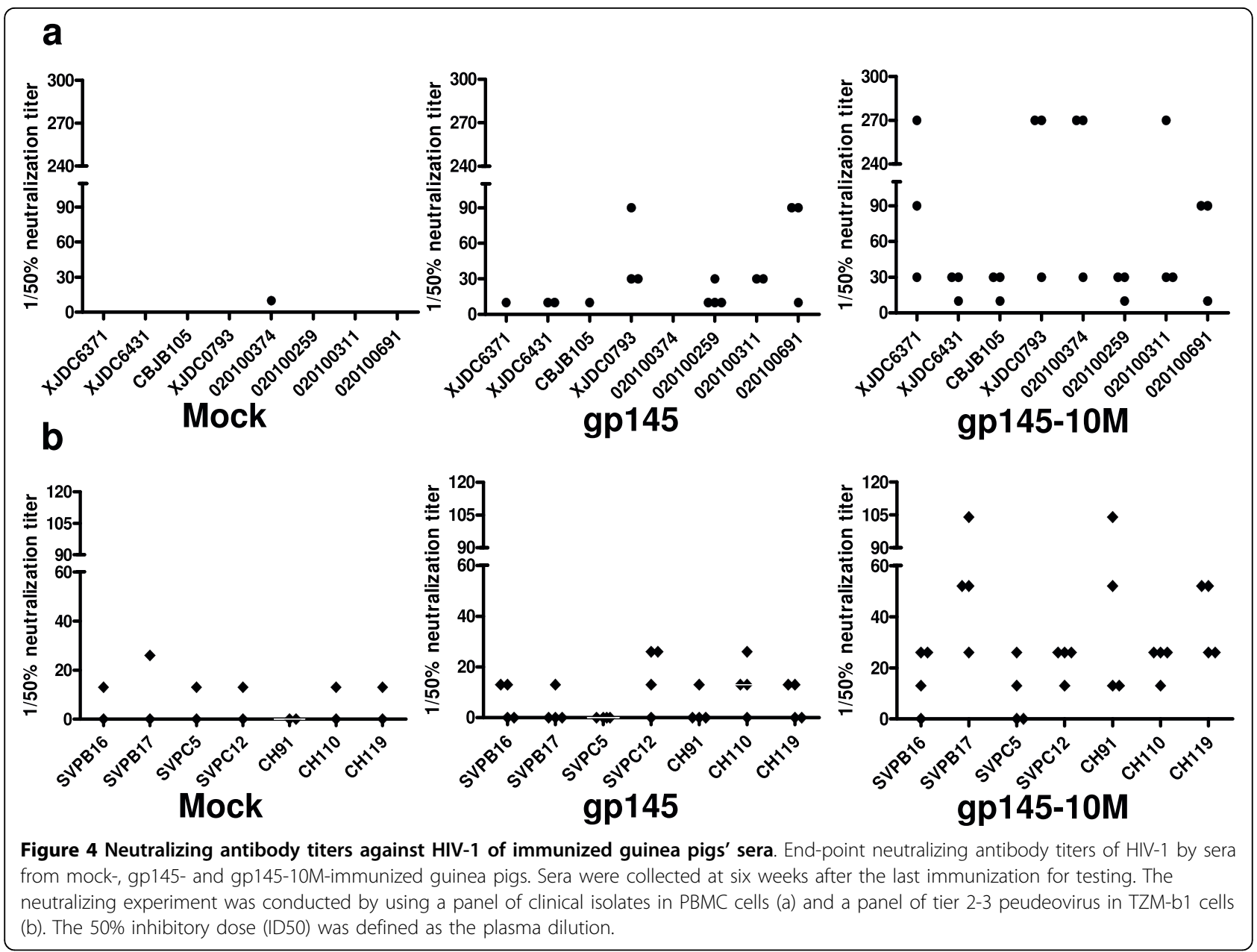

peptide 4876 in the V5 loop and higher antibody titers to peptides 4886 and 4887 in the HR region.

\section{Env-specific T cell immune responses}

HIV-1 ${ }_{\text {cn54 }}$ Env-specific T cell responses were also measured by the IFN- $\gamma$-based ELISPOT assay after stimulation of splenocytes with SHIVchn19 peptides from the ENV1 and ENV2 pools. The ENV1 pool is made up of the first 43 peptides (4830-4871), and the others compose the ENV2 pool (4872-4913). The Env peptides of SHIVchn19 are HIV-1 CN54 Env peptides. The data showed no obvious difference between the gp145- and gp145-10M-immunized mice (Figure 6a-d).

\section{Gp145M1\&2 enhanced immune responses Humoral immune responses}

Further studies were conducted in mice immunized with gp145M1\&2 (composed of mutations of both M1 and M2), gp145M3, gp145M4, and gp145M5 (Figure 1b). Notably, gp145M1\&2 (similarly to gp145-10M) induced higher specific binding antibodies than gp145 ( $\mathrm{p}=$ 0.041). No significant specific binding antibody differences were found in any other group (Figure 2c). Moreover, the sera from the gp145M1\&2-immunized animals neutralized almost all of the $\mathrm{B}^{\prime} / \mathrm{C}$ isolates and $\mathrm{B}^{\prime}$ viruses at a titer greater than 1:24 (Table 2). The sera of the gp145M3- and gp145M4-immunized groups neutralized HIV-1 isolates CBJB248 and 020101300 with an endpoint titer of 1:12 (Table 2). Overall, gp145M1\&2 induced similar potent humoral immunity as gp145-10 $M$ did.

\section{Env-specific $T$ cell immune responses}

The specific cellular responses measured by the IFN- $\gamma$ ELISPOT assay gave additional results in mice. The gp145M1\&2 immunization induced vigorous IFN- $\gamma$ responses $\left(1116 \pm 165 \mathrm{SFC} / 10^{6}\right.$ splenocytes, $\left.\mathrm{N}=5\right)$, which were significantly higher than those elicited in the gp145 group $\left(627 \pm 118 \mathrm{SFC} / 10^{6}\right.$ splenocytes, $\left.\mathrm{N}=5\right)(\mathrm{p}$ $=0.043)$. A two-fold enhancement of the immune response was achieved by the modification (Figure 6e, h). Although the mutations of gp145M1\&2 localized at those epitopes covered by the ENV1 peptide pool, both the ENV1 and the ENV2 peptide pools stimulated 


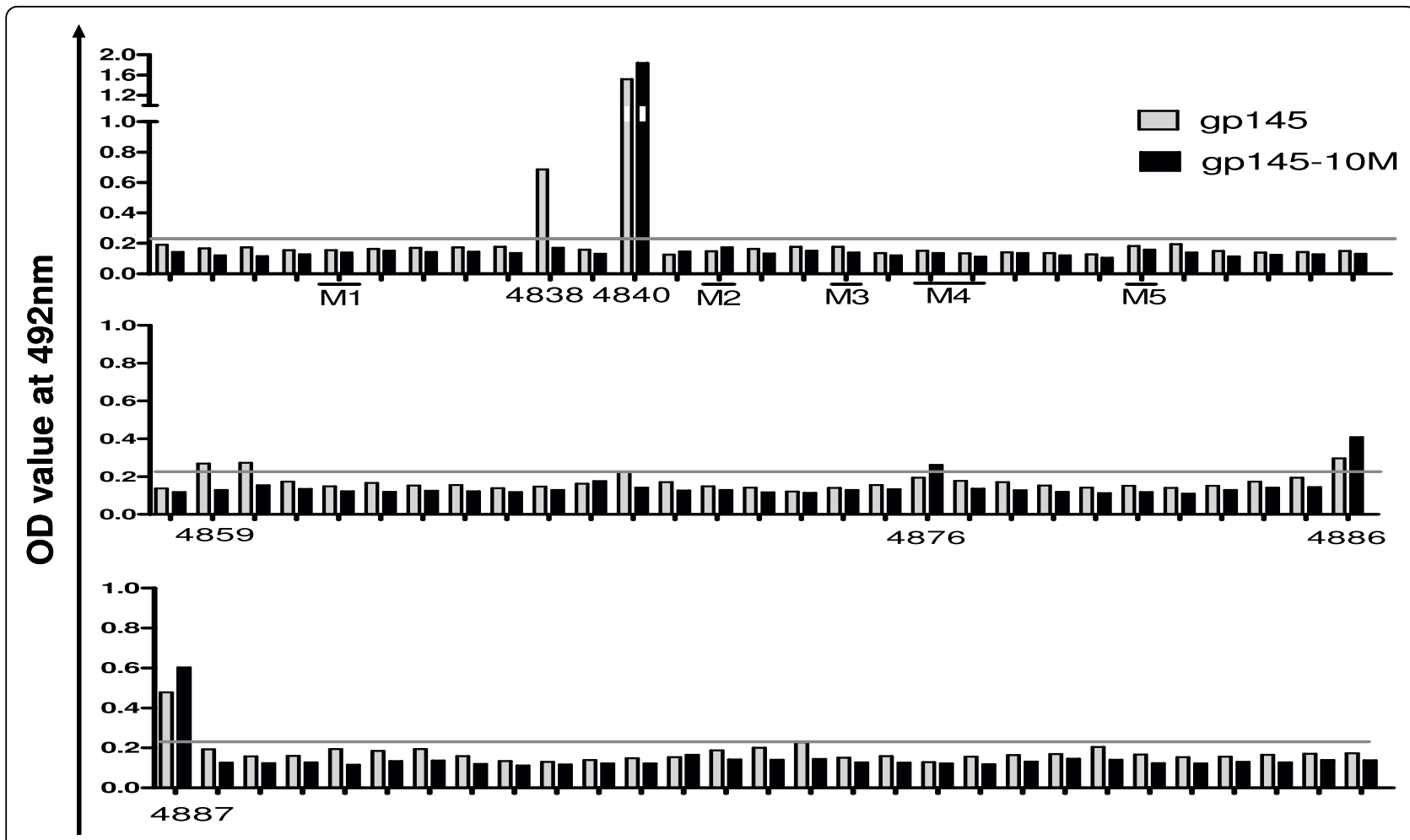

Figure 5 Linear antibody epitope mapping. PLL-ELISA was used to detect the responses of the antibody against each linear peptide. The concentration of each peptide of HIVCN54gp145 was $10 \mu \mathrm{g} / \mathrm{ml}$. In these epitopes, seven were defined as positive (> two-fold background). Epitopes p4838, p4859 and p4860 were only identified in the SV145 group. P4876 was only defined in the SV145-10 M group. The grey line in the figure indicates the threshold value $(0.22)$, which is two times than the average OD values $(0.11)$ from mock controls. Five mutation regions were labeled.

higher T-cell immunities in the gp145M1\&2-immunized group than in the gp145 and gp145-10M-immunized groups (Figure 6f, g).

\section{Gp145M1 elicits the best immunity Humoral immune responses}

Two new mutants, SV145M1 and SV145M2, were designed to evaluate the enhanced immunogenicity induced by gp145M1\&2. (Table 1 ) The mean specific binding antibody titers were 1:1, 1:666, 1:2900, 1:2800 and 1:279 following immunization with SV1.0, SV145, SV145M1\&2, SV145M1 and SV145M2, respectively (Figure 2d). Inoculation with gp145M1\&2 and gp145M1 stimulated higher binding antibodies than any other modified gp145. Although the sera from the mice, immunized with gp145M2, neutralized almost all HIV isolates (whether $\mathrm{B}^{\prime} / \mathrm{C}$ clade or B clade) at a titer greater than 1:12, the gp145M1-immunized animal sera neutralized viruses at a titer higher than 1:24 (Table 2).

\section{Env-specific T cell immune responses}

The results also showed that Env-specific $\mathrm{T}$ cellular immunity was enhanced to a similar level by both the SV145M1\&2 and SV145M1 DNA vaccines to the peptides pool of either ENV1 or ENV2 (Figure 6i, k, $1 \& 6 \mathrm{~m})$. Therefore, gp145M1 appears to be the most important mutation for enhancing the anti-HIV immune response.

\section{Discussion}

The HIV-1 envelope glycoprotein is the primary target for neutralization, and great efforts have been made to enhance the immunogenicity of Env in AIDS vaccine design. Although the primary goal for studies of Env modification is to elicit cross-reactive neutralizing antibodies responses [27,31-38], specific binding antibodies have also been shown to contribute to vaccine-induced protection [28]. Moreover, one study in rhesus monkeys demonstrated that specific $\mathrm{T}$ cellular responses elicited by HIV Env contributed to vaccine-induced protection from challenge viruses carrying a heterologous envelope [39]. Similar T cell results were found in the vaccination with the EIAV vaccine EIAVD9 [40]. Another study showed that specific modifications in HIV Env also enhanced the ability to induce broader $\mathrm{CD} 8+\mathrm{T}$ cell activities [41].

With this information in mind, we performed comparative studies of the structural and functional changes 


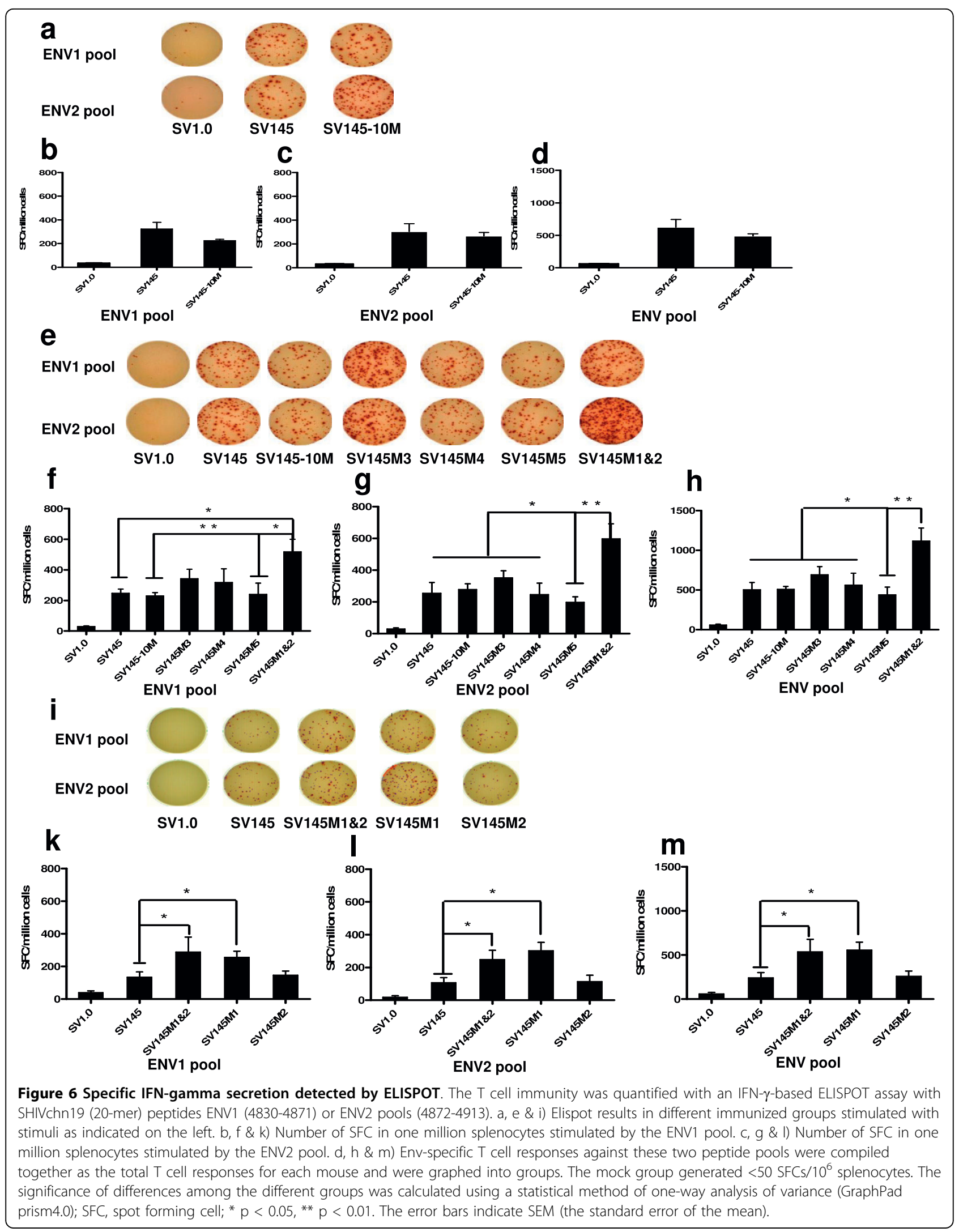




\section{a. gp145 secondary structure prediction}

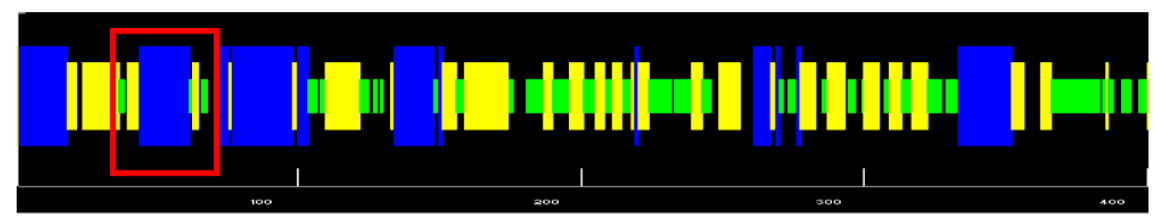

b. gp145M1 secondary structure prediction

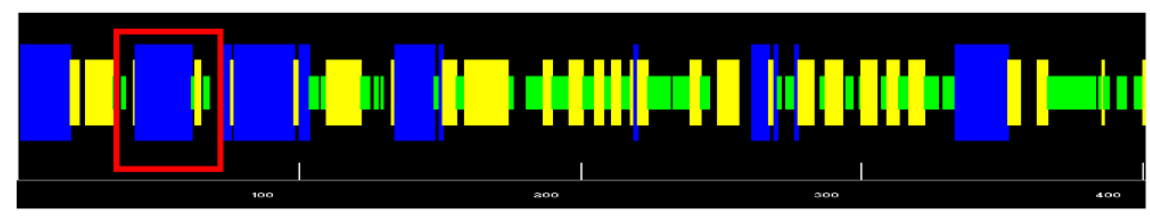

\section{c. gp145 Hydrophilicity profile}

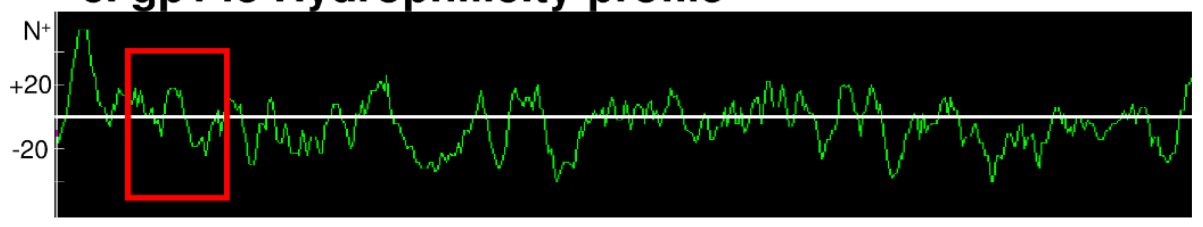

\section{d. gp145M1 Hydrophilicity profile}

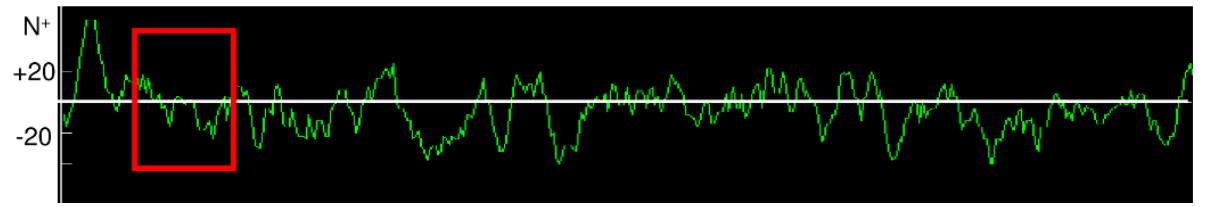

Figure 7 The secondary structure prediction and hydrophilicity changes of antigens. AnthePro5.0 software was applied to predict the secondary structure and hydrophilicity changes of gp145 and gp145M1. The red rectangle labels the changed profiles. a \& b) The secondary structure predictions of gp145 and gp145M1. $\alpha$-helix in blue bar; $\beta$-sheet in orange bar; $\beta$-turn in green bar; others in black bar. c \& d) The difference in hydrophilicity between gp145 and gp145M1. The Y-axis shows the value of predicted hydrophilicity.

in the Env of the EIAV vaccine and wild-type strains. The critical mutations found in EIAV were introduced into HIV Env based on their conserved secondary structure and glycosylation properties [5,6] (Figure 1). The purpose of the modification was to increase the immunogenicity of HIV Env.

The modified immunogen gp145-10 M (containing all 10 mutations) induced broad and high neutralizing antibody titers both in mice and guinea pigs. All primary HIV-1 isolates could be neutralized by the gp145-10Mimmunized sera (Table 2, Figure 3 \&4). Additional studies showed similar results following immunization with gp145M1\&2 and gp145M1 (Table 2). Both neutralizing antibodies and specific binding antibodies were greatly enhanced in quality as well as in quantity (Figure $2 \&$ Table 2).

The PLL-ELISA data showed that antibodies to specific linear epitopes were different between the wild-type gp145- and gp145-10M-immunized groups. However, these different epitopes did not match the mutation sites (Figure 5). We hypothesized that there were conformational changes induced by the modification because the locations of the epitopes were interspersed in the whole envelope. In fact, studies of the secondary structure of these antigens demonstrated one major change in the $\mathrm{C} 1$ region caused by the M1 mutation, in which one $\beta$-sheet was changed to an $\alpha$-helix structure compared to gp145 (Figure 7a, b). Furthermore, a 14amino acid segment within the $\mathrm{C} 1$ region that was originally hydrophobic is now amphipathic (Figure 7c, d). These changes may cause the exposure of some conservative epitopes. In this regard, our data suggest that the mutation in the $\mathrm{C} 1$ region causes a polarity change of the 14 amino acids and that it induces the exposure of conserved epitopes to stimulate stronger and broader neutralizing antibodies. Other mutations elicit fewer changes in the secondary structure but cause no polarity changes (data not shown).

In addition to the potent neutralizing antibodies and specific binding antibodies observed in the group 
immunized with gp145M1 and gp145M1\&2, high levels of secretion of IFN- $\gamma$ specific to the ENV1 and ENV2 peptides pools were induced (Figure 6). Because the mutations were modified at the $\mathrm{C} 1$ and the $\mathrm{V} 1$ regions, the enhancement of specific $\mathrm{T}$ cell response to the ENV2 peptides pool was noteworthy. Future studies will focus on the influence of different mutations on the process of antigen presentation [42-45]. Importantly, this study showed that one amino acid change in the C1 region induced potent anti-HIV-1 responses involving specific binding antibodies, neutralizing antibodies, and cellular immunity.

\section{Methods}

\section{DNA vaccine construction}

HIV-1 CN54 isolated in the early prevalence of HIV-1 in China may be considered as an ancestor strain, though the sequence data to establish this concept remains unavailable. The gp145 gene was acquired using PCR amplification from the codon-optimized gp160 gene of CN54. Then, the SV145 plasmid containing gp145 gene was constructed using vector SV1.0 (pDRVI SV1.0). The SV1.0 vector carries a kanamycin resistance gene and a 72-bp element of the SV40 enhancer. Consensus amino acid mutations were identified in the EIAV Env from the sequence analysis of two wild-type EIAV strains, LN40 and D510, and two vaccine virus strains, DLV and FDDV (vaccine developed through 12 passages in fetal donkey dermal cells from DLV). The amino acid modification sites of gp145 were determined by aligning the envelope of EIAV and HIV-1 CN54 with the sequence of the amino acid, the structure of the variable loop and conserved regions, the location of conserved glycosylation sites and the intra-chain disulfide bond sites [1,5,6,46-48] (Figure 1c). Mutants of gp145 were generated by site-directed mutagenesis with two pairs of the primers (Table 1). The resulting vaccines were designated as SV145M1, SV145M2, SV145M3, SV145M4, SV145M5, SV145M1\&2 and SV145-10 M, respectively. SV145M1 contains the first mutation L42E; SV145M2 contains mutations S128-(deleted) and N129Q; SV145M3 contains one mutation R155E; SV145M4 contains three mutations S179E, E180K and S183Q; SV145M5 also contains three mutations G230R, G232Q and H235Y. SV145M1\&2 was composed of mutations of M1 and M2. SV145-10 M contains all the ten mutations, respectively (Figure $1 \mathrm{~b}$ ). All constructs were confirmed by double-strand gene sequencing.

\section{Recombinant Tiantan vaccinia vaccine (rTV) construction}

Gp145 and gp145-10 M genes were cloned into the pSC65 shuttle plasmid (with a Lac Z gene as a screening marker), which was designed to recombine specifically with the TK gene of the Tiantan vaccinia virus.
Subconfluent monolayers of 143B cells were grown in Eagle's media containing 10\% fetus bovine serum (FBS) and $1 \%$ Penicillin-Streptomycin-L-glutamine. The cells were washed with Eagle's media in the absence of FBS. Five million pfu vaccinia viruses were inoculated 143B cells for one hour at $37^{\circ} \mathrm{C}$ and $5.0 \% \mathrm{CO}_{2}$. Thereafter, the vaccinia-infected cells were further transfected with recombinant shuttle plasmids with Lipofectamine 2000 (CAT\#11668-019, Invitrogen). After a 48-hour incubation, the transfection medium was removed and all wells were covered with $2 \%$ melted low-melting temperature (LMP) agarose mixed with an equal volume of $2 \times$ Eagle's media containing $100 \mu \mathrm{g} / \mathrm{ml} \mathrm{x}$-gal. The blue Lac Z-positive colonies were picked up and further purified in 143B cells under the pressure of a selection media (Eagle's media containing $50 \mu \mathrm{g} / \mathrm{ml} \mathrm{BrdU}$ ). The purified recombinant Tiantan vaccinia viruses were confirmed by PCR amplification of the inserted gp145, gp145-10 M. The generated vaccines were designated as rTV145 and rTV145-10 M. All rTVs were expanded in primary chicken embryo cells.

\section{Immunization of $B A L B / c$ mice}

Female BALB/c mice (six weeks old, 18-22 g) were purchased from the Institute of Laboratory Animal Science, Chinese Academy of Medical Sciences \& Peking Union Medical College. All animals experiments were reviewed and approved by the Institutional Animal Care and Use Committee (IACUC) at the China CDC animal facility and were performed in accordance with relevant guidelines and regulations. A sample of $100 \mu \mathrm{g}$ of purified plasmid DNA was suspended in $100 \mu \mathrm{l}$ of PBS and inoculated intramuscularly into the tibialis anterior four times at intervals of two weeks. The mice were sacrificed at three weeks after the last inoculation. Splenocytes were freshly collected for Elispot assays, and sera were collected and stored at $4^{\circ} \mathrm{C}$ and $-80^{\circ} \mathrm{C}$ for future quantification of antibodies.

\section{Immunization of guinea pigs}

Female Huntley guinea pigs (six weeks old) were purchased from the Center of Laboratory Animal Science, National Institute for the Control of Pharmaceutical and Biological Products. All animal experiments were reviewed and approved by the Institutional Animal Care and Use Committee (IACUC) at the China CDC animal facility and were performed in accordance with relevant guidelines and regulations. A sample of $500 \mu \mathrm{g}$ of purified plasmid DNA of SV1.0, SV145 and SV145-10 M was suspended in $500 \mu \mathrm{l}$ of PBS. A group of four guinea pigs were intramuscularly injected three times at Weeks 0,2 and 4 . Thereafter, guinea pigs in each group were boosted with $1 \times 10^{7}$ pfu recombinant Tiantan Vaccinia-vectored vaccines at six weeks after the last DNA 
inoculation. Sera were collected at four and six weeks after the last inoculation and stored at $4{ }^{\circ} \mathrm{C}$ and $-80^{\circ} \mathrm{C}$ for future quantification of antibodies.

\section{HIV-1 CN54 envelope-specific binding antibody assay}

Purified HIV-1 ${ }_{\mathrm{cn} 54}$ gp120 (more than $85 \%$ purity) was resolved in sodium bicarbonate buffer $(\mathrm{pH} 9.6)$ at a final concentration of $4 \mu \mathrm{g} / \mathrm{ml}$, and $100 \mu \mathrm{l}$ was added to each well of 96-well flat-bottom plates (Costar, NY). Plates were coated at $4^{\circ} \mathrm{C}$ overnight, then washed twice with PBS and blocked at $37^{\circ} \mathrm{C}$ for one hour with blocking solution (PBS containing 5\% skimmed dry milk). Mice sera were serially two-fold diluted in blocking solution, and $100 \mu \mathrm{l}$ of diluted sera was added to each well. After incubating the plates at $37^{\circ} \mathrm{C}$ for one hour, the plates were then washed five times with PBS-T (PBS containing $0.05 \%$ Tween 20 ), and $100 \mu \mathrm{l} /$ well of peroxidase-conjugated anti-mouse immunoglobulin G (diluted 1:2000 in block solution) was added and incubated for $30 \mathrm{~min}$ utes at $37^{\circ} \mathrm{C}$. The wells were washed again, and $100 \mu \mathrm{l}$ of OPD substrate (Cat\# P9187, Sigma Aldrich) was added and incubated for approximately 10 minutes at room temperature. Color development was terminated by the addition of $50 \mu \mathrm{l} /$ well $2 \mathrm{~N}$ sulfuric acid. Antibody reactivity was then determined by measuring the optical density (OD) at $492 \mathrm{~nm}$ with an automated plate reader (Multiscan Ascent, Thermo Corporation, Finland). Endpoint titers were determined by the last dilution whose OD was >two-fold that of the corresponding dilution of the control sera.

\section{Linear antibody epitope mapping}

A method of PLL-ELISA was employed in this study $[28,49]$. PLL (poly-L-leucine, 30-70 kDa, Sigma Aldrich) was dissolved at the concentration of $40 \mu \mathrm{g} / \mathrm{ml}$ in the sodium bicarbonate buffer, and $50 \mu \mathrm{l} /$ well of PLL solution was added to a 96-well ELISA plate and incubated at room temperature for one hour. The plate was washed once with PBS, incubated with $50 \mu \mathrm{l}$ per well of $1 \%(\mathrm{v} / \mathrm{v})$ glutaraldehyde (Sigma Aldrich) in PBS at room temperature for 15 minutes and washed twice with PBS. Then, $50 \mu \mathrm{l} /$ well of each peptide of SHIVchn19 (kindly provided by the NIH Research and Reference Reagent Program, NIAIDS, NIH, Cat\# 4974: The Env of SHIVchn19 is CN54 Env) in PBS was added at the concentration $10 \mu \mathrm{g} / \mathrm{ml}$. The plates were incubated overnight at $4^{\circ} \mathrm{C}$ and then washed twice with PBS. Reactive aldehyde sites were blocked by the addition of $1 \mathrm{M}$ glycine, at $200 \mu \mathrm{l} /$ well, for one hour at room temperature. The plates were washed twice again with PBS and blocked with $1 \mathrm{M}$ glycine, at $100 \mu \mathrm{l} /$ well, for one hour at room temperature, and then they were incubated with $100 \mu \mathrm{l} /$ well of $0.5 \%$ skimmed dry milk:0.5\% gelatin (dissolved in PBS) for one hour. Mouse sera were diluted at the ratio of $1: 100$ in PBS containing $5 \%$ skimmed dry milk, and $50 \mu \mathrm{l} /$ well of diluted sera was added into the plates in duplicate and incubated at $37^{\circ} \mathrm{C}$ for one hour. The plates were then washed four times with PBS-T, incubated with $50 \mu \mathrm{l} /$ well of diluted HRPlinked second antibody (1:2000 diluted in PBS containing 2\% skimmed dry milk, CAT\# ZB-2305, Beijing Zhongshan Biotech) at $37^{\circ} \mathrm{C}$ for one hour, washed five times again with PBS-T and finally incubated with $50 \mu \mathrm{l} /$ well of OPD substrate at room temperature in a dark place for about 10 minutes. The reaction was terminated with $50 \mu \mathrm{l} /$ well $2 \mathrm{~N}$ sulfuric acid, and the OD value for each well was read with an automated plate reader at $492 \mathrm{~nm}$. OD values of experimental settings were displayed after subtraction of the background (that is the OD value generated with sera from mock vector control groups against the corresponding peptide), and >two-fold average OD values of background were considered as positive.

\section{HIV virus preparation and titration}

HIV-1 primary viruses were isolated from patients' peripheral blood mononuclear cells (PBMCs) by FicollPaque gradient centrifugation (Amersham biosciences) and co-cultured with phytohemagglutinin- (PHA)-stimulated PBMCs from two HIV-1-seronegative human donors. The cells were maintained in RPMI 1640 medium (Gibco) containing $20 \mathrm{U} / \mathrm{ml}$ of recombinant interleukin-2 (IL-2; National Institutes of Health; Bethesda, Maryland, USA), 1\% penicillin and streptomycin (P/S), 2 $\mathrm{mM}$ glutamine and 10\% FBS. Five clade B'/C (CRF07) HIV-1 (XJDC6371, XJDC6431, XJDC0793, CBJB105, CBJB248) and four clade B' HIV-1 (020100374, 020100259, 020100311, 020100691) clinical isolates were used for this study [50]. Two clade B HIV-1 isolates (SVPB16, SVPB17), two clade C HIV-1 isolates (SVPC5, SVPC12) and three B'/C HIV-1 (CH91, CH110, CH119) tier 2 pseudotyped viruses were used in neutralizing antibody assay. There is no env sequence of these viruses matched mutations.

The 50\% tissue culture infectious dose (TCID50) of a single thawed aliquot of each batch of virus was determined in TZM-BL cells. For TCID50 measurements, serial five-fold dilutions of viruses were made in quadruplicate wells in 96-well culture plates in a total volume of $100 \mu \mathrm{l}$ of growth medium for a total of 11 dilution steps. Freshly trypsinized cells $(10,000$ cells in $100 \mu \mathrm{l}$ of growth medium containing $75 \mu \mathrm{g} / \mathrm{ml}$ DEAE-dextran) were added to each well, and the plates were incubated at $37^{\circ} \mathrm{C}$ in a humidified environment with $5 \% \mathrm{CO}_{2}$. After a 48-hour incubation, $100 \mu \mathrm{l}$ of culture medium was removed from each well and $100 \mu \mathrm{l}$ of Bright-Glo reagent (Luciferase Assay system, Promega) was added to the cells. After a two-minute incubation at room 
temperature to allow cell lysis, $150 \mu \mathrm{l}$ of cell lysate was transferred to 96-well black solid plates (CorningCostar) for measurements. The plates were read immediately with a 1420 Multilabel Counter (PerkinElmer). Wells producing relative luminescence units (RLU) $>$ three-fold background were scored as positive. Indinavir was added to the medium at a final concentration of $1 \mu \mathrm{M}$ to prevent progeny virion production.

\section{Neutralizing antibody assay}

All mice and guinea pigs sera were heat-inactivated at $56^{\circ} \mathrm{C}$ for one hour prior to assaying. Volumes of $25 \mu \mathrm{l}$ of sera from different immunized mice groups were diluted in $125 \mu \mathrm{l}$ of DEAE-GM solution containing 10\% heat-inactivated FBS, $50 \mu \mathrm{g} / \mathrm{ml}$ gentamicin and $1 \mu \mathrm{M}$ indinavir to a 1:6 dilution. The diluted sera were further two-fold diluted as 1:12 and 1:24 in 96-well plates. Guinea pigs' sera were three-fold diluted from titer 1:10 to 1:270. Thereafter, each well received $50 \mu \mathrm{l}$ of cell-free virus $\left(200 \mathrm{TCID}_{50}\right)$. After one hour of incubation, 10,000 TZM-bl cells were added to each well. Plates were incubated for 48 hours. Then, $100 \mu \mathrm{l}$ of media removed, and Bright-Glo substrate was added to each well. Percentages of RLU reduction were calculated as (1- (Average RLU of duplicates with sample sera control wells)/(Average RLU from mock control sera control wells)) X100\%. Neutralizing antibody titers were expressed as the reciprocal of the serum dilution required to reduce RLU by $50 \%$.

\section{IFN- $\gamma$ ELISPOT assay}

HIV-1-specific $T$ cell responses were measured using the IFN- $\gamma$ ELISPOT assay kit (BD Biosciences, United States). Plates were coated with purified anti-mouse IFN $\gamma$ at a concentration of $5 \mu \mathrm{g} / \mathrm{ml}$, incubated at $4^{\circ} \mathrm{C}$ overnight, then washed once with RPMI1640 containing $10 \%$ FBS and 1\% Penicillin-Streptomycin-L-glutamine and finally blocked for two hours at room temperature. Mouse splenocytes $\left(2 \times 10^{5}\right)$ were added to wells in duplicates. Cells were stimulated with the HIV-1 CN54 ENV1 or ENV2 peptide pools at $4 \mu \mathrm{g} / \mathrm{ml}$ each peptide. The [SHIVchn19 (20-mer) peptides] ENV1 pool is made up of the first 43 peptides (4830-4871), and others compose the ENV2 pool (4872-4913). The positive control was stimulated with PMA at $50 \mathrm{ng} / \mathrm{ml}$ and ionomycin at $1 \mu \mathrm{g} / \mathrm{ml}$, and the negative control was stimulated with medium only. The splenocytes were incubated at $37^{\circ} \mathrm{C}$ and $5.0 \% \mathrm{CO}_{2}$ for 24 hours and then lysed with sterile water. Plates were washed three times with PBS-T prior to one-hour incubation with biotinylated anti-mouse IFN- $\gamma$ antibody, followed by the addition of streptavidinHRP for one hour at $37^{\circ} \mathrm{C}$. Plates were washed again and developed with $100 \mu \mathrm{l}$ of AEC substrate solution for 10 30 minutes. The reaction was stopped by washing with distilled water. IFN- $\gamma$ spots were analyzed by an automated ELISPOT plate reader (ImmunoSpot, C.T.L). Spot-forming cells (SFCs) were defined as the average number of spots in duplicate wells per $10^{6}$ PBMCs.

\section{Acknowledgements}

We are grateful to Jay A. Levy, University of California, San Francisco, for helpful advice in the revision of this article. We thank the participants of Chao Qiu and Li Ren for their kind help in animal experiments. We also thank Danli Duan, Hong Peng and Chao Wu for technical support. We thank the AIDS Research and Reference Reagent Program, National Institutes of Health, for providing SHIV-1chn19 peptides complete set. This research was supported by China Comprehensive Integrated Programs for Research on AIDS (CIPRA, U19A151915), the National Institute of Allergy and Infectious Diseases, National Institute of Health, USA, by the National Mega Projects on Key Infectious Disease Control (2008ZX10001-010) of China Ministry of Science and Technology, by the International Cooperative Grant of China Ministry of Science and Technology(2009DFB30420), and by China National Program on Key Basic Research Projects (973 Program) (No. 2005CB522903, 2005CB523103) of China Ministry of Science and Technology.

\section{Competing interests}

The authors declare that they have no competing interests.

\section{Authors' contributions}

YS designed the research and wrote the paper; LL designed, performed the research and wrote the paper; LW and HL helped to design the research; YW, JS, HL, and LM contributed to perform the research. All authors read and approved the final manuscript.

\section{Author details}

${ }^{1}$ State Key Laboratory for Infectious Diseases Prevention and Control, National Center for AIDS/STD Control and Prevention, Chinese Center for Disease Control and Prevention, 155 Changbai Road, Changping District, Beijing 102206, China. ${ }^{2}$ State Key Laboratory of Virology, Wuhan Institute of Virology, Chinese Academy of Sciences, No. 44 Xiaohongshan Road, Wu Chang District, Wuhan 430071, China. ${ }^{3}$ Department of Medicine, University of California, San Francisco, San Francisco, CA 94143, USA. ${ }^{4}$ Science Research Department, Shanghai Public Health Clinical Center, Public Health Clinical Center affiliated to Fudan University, Shanghai, MD 201508, China.

Received: 7 May 2010 Accepted: 1 September 2010

Published: 1 September 2010

\section{References}

1. Leroux C, Cadore JL, Montelaro RC: Equine Infectious Anemia Virus (EIAV): what has HIV's country cousin got to tell us? Vet Res 2004, 35:485-512.

2. Liang $H, H e X$, Shen RX, Tong X, Ma Y, Xiang WH, Zhang XY, Shao YM: Combined Amino Acid Mutations Occurring in the Envelope Closely Correlate with Pathogenicity of EIAV. Archives of Virology 2006, 151:1387-1403.

3. Gonda MA, Braun MJ, Clements JE, Pyper JM, Wong-Staal F, Gallo RC, Gilden RV: Human T-cell lymphotropic virus type III shares sequence homology with a family of pathogenic lentiviruses. Proc Natl Acad Sci USA 1986, 83:4007-4011.

4. Clements JE, Zink MC: Molecular biology and pathogenesis of animal lentivirus infections. Clin Microbiol Rev 1996, 9:100-117.

5. Hotzel I: Conservation of the human immunodeficiency virus type 1 gp120 V1/V2 stem/loop structure in the equine infectious anemia virus (EIAV) gp90. AIDS Res Hum Retroviruses 2003, 19:923-924.

6. Li H, Zhang X, Fan X, Shen T, Tong X, Shen R, Shao Y: A conservative domain shared by HIV gp120 and EIAV gp90: implications for HIV vaccine design. AIDS Res Hum Retroviruses 2005, 21:1057-1059.

7. Miller RJ, Cairns JS, Bridges S, Sarver N: Human immunodeficiency virus and AIDS: insights from animal lentiviruses. J Virol 2000, 74:7187-7195.

8. McGuire TC, O'Rourke Kl, Perryman LE: Immunopathogenesis of equine infectious anemia lentivirus disease. Dev Biol Stand 1990, 72:31-37.

9. Tang $\mathrm{H}$, Kuhen $\mathrm{KL}$, Wong-Staal $\mathrm{F}$ : Lentivirus replication and regulation. Annu Rev Genet 1999, 33:133-170. 
10. Sellon DC, Fuller FJ, McGuire TC: The immunopathogenesis of equine infectious anemia virus. Virus Res 1994, 32:111-138.

11. Cheevers WP, McGuire TC: Equine infectious anemia virus: immunopathogenesis and persistence. Rev Infect Dis 1985, 7:83-88

12. Bogers WM, Cheng-Mayer C, Montelaro RC: Developments in preclinical AIDS vaccine efficacy models. Aids 2000, 14(Suppl 3):S141-151.

13. Craigo JK, Zhang B, Barnes S, Tagmyer TL, Cook SJ, Issel CJ, Montelaro RC: Envelope variation as a primary determinant of lentiviral vaccine efficacy. Proc Natl Acad Sci USA 2007, 104:15105-15110.

14. Hammond SA, Cook SJ, Lichtenstein DL, Issel CJ, Montelaro RC: Maturation of the cellular and humoral immune responses to persistent infection in horses by equine infectious anemia virus is a complex and lengthy process. J Virol 1997, 71:3840-3852.

15. Hammond SA, Raabe ML, Issel CJ, Montelaro RC: Evaluation of antibody parameters as potential correlates of protection or enhancement by experimental vaccines to equine infectious anemia virus. Virology 1999, 262:416-430

16. Montelaro RC, Cole KS, Hammond SA: Maturation of immune responses to lentivirus infection: implications for AIDS vaccine development. AIDS Res Hum Retroviruses 1998, 14(Suppl 3):S255-259.

17. Payne SL, Fang FD, Liu CP, Dhruva BR, Rwambo P, Issel CJ, Montelaro RC: Antigenic variation and lentivirus persistence: variations in envelope gene sequences during EIAV infection resemble changes reported for sequential isolates of HIV. Virology 1987, 161:321-331.

18. Shen RX, Xu ZD, HE YS, Zhang SX: Development of a EIAV donkey leucocyte attenuated vaccine. China Agriculture Sciences 1979, 4:1-15.

19. Dong JP, Wang ZY, Peng DC, Shen RX: Studies on the equine infectious anemia fetal donkey dermal cell-adapted attenuated vaccine and its efficacy. Chinese Journal of Animal and Poultry Infectious Diseases 1989, 3:77-82.

20. Johnson RP, Lifson JD, Czajak SC, Cole KS, Manson KH, Glickman R, Yang J, Montefiori DC, Montelaro R, Wyand MS, Desrosiers RC: Highly attenuated vaccine strains of simian immunodeficiency virus protect against vaginal challenge: inverse relationship of degree of protection with level of attenuation. J Virol 1999, 73:4952-4961.

21. Li F, Craigo JK, Howe L, Steckbeck JD, Cook S, Issel C, Montelaro RC: A live attenuated equine infectious anemia virus proviral vaccine with a modified S2 gene provides protection from detectable infection by intravenous virulent virus challenge of experimentally inoculated horses. J Virol 2003, 77:7244-7253.

22. Wyand MS, Manson K, Montefiori DC, Lifson JD, Johnson RP, Desrosiers RC: Protection by live, attenuated simian immunodeficiency virus against heterologous challenge. J Virol 1999, 73:8356-8363.

23. Payne SL, Pei XF, Jia B, Fagerness A, Fuller FJ: Influence of long terminal repeat and env on the virulence phenotype of equine infectious anemia virus. J Virol 2004, 78:2478-2485.

24. McGuire TC, Leib SR, Mealey RH, Fraser DG, Prieur DJ: Presentation and binding affinity of equine infectious anemia virus CTL envelope and matrix protein epitopes by an expressed equine classical MHC class I molecule. J Immunol 2003, 171:1984-1993.

25. Jin S, Zhang B, Weisz OA, Montelaro RC: Receptor-mediated entry by equine infectious anemia virus utilizes a $\mathrm{pH}$-dependent endocytic pathway. J Virol 2005, 79:14489-14497.

26. Cole KS, Murphey-Corb M, Narayan O, Joag SV, Shaw GM, Montelaro RC: Common themes of antibody maturation to simian immunodeficiency virus, simian-human immunodeficiency virus, and human immunodeficiency virus type 1 infections. J Virol 1998, 72:7852-7859.

27. Clements JE, Montelaro RC, Zink MC, Amedee AM, Miller S, Trichel AM, Jagerski B, Hauer D, Martin LN, Bohm RP, Murphey-Corb M: Crossprotective immune responses induced in rhesus macaques by immunization with attenuated macrophage-tropic simian immunodeficiency virus. J Virol 1995, 69:2737-2744.

28. Cole KS, Rowles JL, Jagerski BA, Murphey-Corb M, Unangst T, Clements JE, Robinson J, Wyand MS, Desrosiers RC, Montelaro RC: Evolution of envelope-specific antibody responses in monkeys experimentally infected or immunized with simian immunodeficiency virus and its association with the development of protective immunity. J Virol 1997, 71:5069-5079.

29. Craigo JK, Durkin S, Sturgeon TJ, Tagmyer T, Cook SJ, Issel CJ, Montelaro RC: Immune suppression of challenged vaccinates as a rigorous assessment of sterile protection by lentiviral vaccines. Vaccine 2007, 25:834-845.
30. Liu L, Wan Y, Xu J, Huang X, Wu L, Liu Y, Shao Y: Immunogenicity comparison between codon optimized HIV-1 CRF BC_07 gp140 and gp145 vaccines. AIDS Res Hum Retroviruses 2007, 23:1396-1404.

31. Choudhry V, Zhang MY, Sidorov IA, Louis JM, Harris I, Dimitrov AS, Bouma P, Cham F, Choudhary A, Rybak SM, Fouts T, Montefiori DC, Broder CC, Quinnan GV Jr, Dimitrov DS: Cross-reactive HIV-1 neutralizing monoclonal antibodies selected by screening of an immune human phage library against an envelope glycoprotein (gp140) isolated from a patient (R2) with broadly HIV-1 neutralizing antibodies. Virology 2007, 363:79-90.

32. Fouts T, Godfrey K, Bobb K, Montefiori D, Hanson CV, Kalyanaraman VS, DeVico A, Pal R: Crosslinked HIV-1 envelope-CD4 receptor complexes elicit broadly cross-reactive neutralizing antibodies in rhesus macaques. Proc Natl Acad Sci USA 2002, 99:11842-11847.

33. Haynes BF, Montefiori DC: Aiming to induce broadly reactive neutralizing antibody responses with HIV-1 vaccine candidates. Expert Rev Vaccines 2006, 5:347-363.

34. LaCasse RA, Follis KE, Trahey M, Scarborough JD, Littman DR, Nunberg JH: Fusion-competent vaccines: broad neutralization of primary isolates of HIV. Science 1999, 283:357-362.

35. Moulard M, Phogat SK, Shu Y, Labrijn AF, Xiao X, Binley JM, Zhang MY, Sidorov IA, Broder CC, Robinson J, Parren PW, Burton DR, Dimitrov DS: Broadly cross-reactive HIV-1-neutralizing human monoclonal Fab selected for binding to gp120-CD4-CCR5 complexes. Proc Natl Acad Sci USA 2002, 99:6913-6918.

36. Quinnan GV, Yu XF, Lewis MG, Zhang PF, Sutter G, Silvera P, Dong M, Choudhary A, Sarkis PT, Bouma P, Zhang Z, Montefiori DC, Vancott TC, Broder CC: Protection of rhesus monkeys against infection with minimally pathogenic simian-human immunodeficiency virus: correlations with neutralizing antibodies and cytotoxic T cells. J Virol 2005, 79:3358-3369.

37. Zhang PF, Cham F, Dong M, Choudhary A, Bouma P, Zhang Z, Shao Y, Feng YR, Wang L, Mathy N, Voss G, Broder CC, Quinnan GV Jr: Extensively cross-reactive anti-HIV-1 neutralizing antibodies induced by gp140 immunization. Proc Natl Acad Sci USA 2007, 104:10193-10198.

38. Kraft Z, Derby NR, McCaffrey RA, Niec R, Blay WM, Haigwood NL, Moysi E, Saunders CJ, Wrin T, Petropoulos CJ, McElrath MJ, Stamatatos L: Macaques infected with a CCR5-tropic simian/human immunodeficiency virus (SHIV) develop broadly reactive anti-HIV neutralizing antibodies. J Virol 2007, 81:6402-6411.

39. Amara RR, Smith JM, Staprans SI, Montefiori DC, Villinger F, Altman JD, O'Neil SP, Kozyr NL, XU Y, Wyatt LS, Earl PL, Herndon JG, McNicholl JM, McClure HM, Moss B, Robinson HL: Critical role for Env as well as Gag-Pol in control of a simian-human immunodeficiency virus $89.6 \mathrm{P}$ challenge by a DNA prime/recombinant modified vaccinia virus Ankara vaccine. $J$ Virol 2002, 76:6138-6146.

40. Tagmyer TL, Craigo JK, Cook SJ, Even DL, Issel CJ, Montelaro RC: Envelope Determinants of Eiav Vaccine Protection and the Effects of Sequence Variation on Immune Recognition. J Virol 2008.

41. Kiszka I, Kmieciak D, Gzyl J, Naito T, Bolesta E, Sieron A, Singh SP, Srinivasan A, Trinchieri G, Kaneko Y, Kozbor D: Effect of the V3 loop deletion of envelope glycoprotein on cellular responses and protection against challenge with recombinant vaccinia virus expressing gp160 of primary human immunodeficiency virus type 1 isolates. J Virol 2002, 76:4222-4232.

42. Cao J, Sullivan N, Desjardin E, Parolin C, Robinson J, Wyatt R, Sodroski J: Replication and neutralization of human immunodeficiency virus type 1 lacking the V1 and V2 variable loops of the gp120 envelope glycoprotein. J Virol 1997, 71:9808-9812.

43. Johnson WE, Morgan J, Reitter J, Puffer BA, Czajak S, Doms RW, Desrosiers RC: A replication-competent, neutralization-sensitive variant of simian immunodeficiency virus lacking 100 amino acids of envelope. J Virol 2002, 76:2075-2086.

44. Stamatatos $L$, Wiskerchen $M$, Cheng-Mayer C: Effect of major deletions in the V1 and V2 loops of a macrophage-tropic HIV type 1 isolate on viral envelope structure, cell entry, and replication. AIDS Res Hum Retroviruses 1998, 14:1129-1139.

45. Walter BL, Wehrly K, Swanstrom R, Platt E, Kabat D, Chesebro B: Role of low CD4 levels in the influence of human immunodeficiency virus type 1 envelope $\mathrm{V} 1$ and $\mathrm{V} 2$ regions on entry and spread in macrophages. $J$ Virol 2005, 79:4828-4837. 
46. Phogat $S$, Wyatt R: Rational modifications of HIV-1 envelope glycoproteins for immunogen design. Curr Pharm Des 2007, 13:213-227.

47. Lin G, Nara PL: Designing immunogens to elicit broadly neutralizing antibodies to the HIV-1 envelope glycoprotein. Curr HIV Res 2007, 5:514-541.

48. Hotzel I, Cheevers WP: Conservation of human immunodeficiency virus type $1 \mathrm{gp} 120$ inner-domain sequences in lentivirus and type A and B retrovirus envelope surface glycoproteins. J Virol 2001, 75:2014-2018.

49. Cole KS, Paliotti MJ, Murphey-Corb M, Montelaro RC: Maturation of envelope-specific antibody responses to linear determinants in monkeys inoculated with attenuated SIV. J Med Primatol 2000, 29:220-230.

50. Ma L, Guo Y, Yuan L, Huang Y, Sun J, Qu S, Yu X, Meng Z, He X, Jiang S, Shao $Y$ : Phenotypic and genotypic characterization of Human Immunodeficiency Virus type I CRF07_BC strains circulating in the Xinjiang Province of China. Retrovirology 2009, 6:45.

doi:10.1186/1742-4690-7-71

Cite this article as: Liu et al: Broader HIV-1 neutralizing antibody responses induced by envelope glycoprotein mutants based on the EIAV attenuated vaccine. Retrovirology 2010 7:71.

\section{Submit your next manuscript to BioMed Central} and take full advantage of:

- Convenient online submission

- Thorough peer review

- No space constraints or color figure charges

- Immediate publication on acceptance

- Inclusion in PubMed, CAS, Scopus and Google Scholar

- Research which is freely available for redistribution

Submit your manuscript at www.biomedcentral.com/submit 